\title{
Brucella seroprevalence in cattle near a wildlife reserve in Kenya
}

\author{
Sofie Enström ${ }^{1}$, Daniel Nthiwa ${ }^{2,3}$, Bernard Bett ${ }^{2}$, Amanda Karlsson ${ }^{1}$, Silvia Alonso ${ }^{4}$ and Johanna F. Lindahl $1,2,5^{*}$
}

\begin{abstract}
Objectives: Brucellosis is caused by bacteria from the genus Brucella which infect human and domestic animals as well as wildlife. The Maasai Mara National Reserve has vast populations of wild ruminants such as buffaloes and wildebeest which could contribute to the risk of brucellosis in livestock, and the surrounding pastoralist communities grazing cattle in and around the reserve may be exposed to a higher risk of zoonotic diseases like brucellosis due to the close contact with livestock. In this study, cattle from three villages at varying distance from the reserve, were screened for antibodies against Brucella abortus.

Results: In total, 12.44\% of 225 sampled animals were seropositive, with more females (15\%) infected than males (5\%). Seroprevalence was higher in livestock closer to Maasai Mara with the cattle in the village Mara Rianta having an odds ratio of 7.03 compared to Endoinyo Narasha further away (95\% Cl 1.4-11.1, p = 0.003), suggesting that a closer contact with wildlife may increase the circulation of infectious diseases between livestock and wild life. Symptoms consistent with brucellosis were reported to occur in both humans and animals, and we thus conclude that brucellosis may be an important problem, both for the health and the economy.
\end{abstract}

Keywords: Zoonosis, Brucella abortus, Livestock-wildlife interface, Pastoralism, Africa

\section{Introduction}

In sub-Saharan Africa, livestock are essential for the livelihood of many families, and the health of livestock, humans and their economic welfare are closely linked [1]. Zoonotic diseases create a double burden on the households with both human and animal morbidity [2]. Brucellosis is a severe disease for farmers since it does not only cause serious chronic disease in humans and suffering in their animals, but also a decreased production since the disease is associated with abortions and reproductive failures in the livestock [3].

In cattle the infection is predominantly caused by $B$. abortus, sometimes by $B$. melitensis (more common in small ruminants) and occasionally by $B$. suis [4-6]. Different wildlife species, especially ruminants, provide a potential reservoir of brucellosis, which has been suggested to increase the risk infections in livestock [7].

\footnotetext{
*Correspondence: J.Lindahl@cgiar.org

${ }^{5}$ Department of Medical Biochemistry and Microbiology, Uppsala University, Uppsala, Sweden

Full list of author information is available at the end of the article
}

In Kenya, awareness of brucellosis is low among livestock-keepers and healthcare staff, and because of the general symptoms and the limited availability of laboratory facilities, diagnosis is not easy $[8,9]$. Moreover, some of the areas with high cultural and economic dependence on livestock are close to wildlife protected areas, such as the Maasai Mara national reserve. The aim of this study was to determine the current seroprevalence of bovine brucellosis and the associated exposure factors for transmission, in three villages close to Maasai Mara.

\section{Main text \\ Methods \\ Three villages (Lemek, Mara Rianta and Endoinyo Narasha) were selected purposively to represent areas with expected differences in livestock-wildlife interac- tion based on the distance to the national reserve. Both Lemek and Endoinyo Narasha represented areas with less livestock-wildlife overlap. In Lemek there was free graz- ing; in Endoinyo Narasha sedentary grazing systems in fenced lands were being adopted, while Mara Rianta had}


high wildlife-livestock interactions due to livestock grazing in the park and communal grazing lands.

The sample size was determined by logistic possibilities. Twenty-five households, all keeping livestock, were randomly selected in each village. Livestock owners were interviewed using a questionnaire translated to Swahili and Maa, where they were asked to answer questions about animal keeping, grazing strategies, herd sizes, experienced signs of illness and other significant details that could be of importance to the study (Additional file 1). The questionnaire was developed by experts at ILRI and pre-tested in the field. Three cattle over 1 year were randomly selected (excluding large bulls and aggressive animals for safety reasons) in each herd for blood sampling. The serum was analyzed in duplicates using an indirect Enzyme-Linked Immunosorbent assay (ELISA); PrioCHECK ${ }^{\circledR}$ Brucella Antibody 2.0 ELISA (Thermo Fisher Scientific) according to manufacturer's instructions. Univariable analyses for risk factors for seropositivity was done using Stata (STATA 14, StataCorp LP, USA). A risk score was calculated adding all risk practices; whether cattle are let to graze inside the national reserve; whether cattle mix with other herds while grazing; whether cattle mix with other herds at watering points; whether cattle share trek route with other herds; whether herds share water point on trek; whether farmer has bought livestock from other farms; whether working personnel visit other livestock holdings; and whether vehicles have access to farm. Correction for multiple comparisons was not done. Data is provided as Additional file 2 .

The study had ethical approval from International Livestock Research Institute (ILRI) animal care and use committee (IACUC Approval 2016-20).

\section{Results}

A total of 225 animals were sampled, and 28 of them [12.44\%; 95\% confidence interval (CI) 7.71-15.41] were seropositive (Table 1). None of the farmers indicated that

Table 1 Distribution of Brucella seropositive cattle in Maasai Mara national reserve in Kenya, divided into study sites and sex

\begin{tabular}{lcccl}
\hline & Total & Positive & \% Positive & $\mathbf{9 5 \% ~ C l}$ \\
\hline Total & 225 & 28 & 12.44 & $7.71-15.41$ \\
Female & 166 & 25 & 15.06 & $10.41-21.29$ \\
Male & 59 & 3 & 5.08 & $1.74-13.92$ \\
Lemek & 75 & 8 & 10.67 & $5.50-19.66$ \\
Mara Rianta & 75 & 17 & 22.67 & $14.66-33.34$ \\
Endoinyo Narasha & 75 & 3 & 4.00 & $1.37-11.11$ \\
\hline
\end{tabular}

they had ever vaccinated livestock against brucellosis. More animals, 22.7\% (95\% CI 14.7-33.3), were positive in Mara Rianta and the odds ratio (OR) was $7.03(\mathrm{p}=0.003)$ higher than Endoinyo Narasha, where seroprevalence was $4.0 \%$ (95\% CI 1.4-11.1), and OR was $2.45(\mathrm{p}=0.053)$ higher for Mara Rianta than in Lemek where the prevalence was 10.7 (95\% CI 5.5-19.7). Females had a higher risk (OR 4.0, $\mathrm{p}=0.046$ ) of being seropositive compared to males, with $25 / 166$ females (15.1\%, 95\% CI 10.4-21.3) being positive compared to $3 / 59$ males $(5.1 \%$, 95\% CI 1.7-13.9). All three positive males were sampled in Mara Rianta.

Twenty farms (26.7\%) had one or more Brucellainfected cattle. During the last year, many farmers had experienced abortion (or loss of pregnancy, or stillbirth) in their cows (68, 48 and 36\% in Mara Rianta, Lemek and Endoinyo Narasha respectively). In 13 of the infected farms (65\%), the farmer reported abortions during the last 1 year. The odds ratio of having had abortion if $\mathrm{Bru}$ cella was present in a farm was 2.2 higher than if Brucella was not present (CI 0.7-6.4), and in $34.2 \%$ of the farms that have experienced abortion in cattle the last 1 year, the farm was positive for Brucella, in even, antibodies against Brucella was present in serum from one or more of the three sampled animals (Table 2).

All farms had at least one bull for breeding and practiced natural mating. All the participants reported that animals had regular contact with wild ungulates and other cattle. Farms in Mara Rianta were generally larger compared to Lemek and Endoinyo Narasha (Table 3). Clinical pictures compatible with brucellosis were also reported in humans handling livestock. The most common was headache (48, 60 and 64\% in Mara Rianta, Lemek and Endoinyo Narasha respectively), muscle, joint and back pain (52, 56 and 64\% in Mara Rianta, Lemek and Endoinyo Narasha respectively) and fever (48, 44 and $40 \%$ in Mara Rianta, Lemek and Endoinyo Narasha respectively) (Table 3 ).

All farms had at least five risk factors reported, with a higher average in Mara Rianta (7.6), than Lemek (7.0) and Endoinyo Narasha (6.8). Seropositive farms generally did have a higher risk score (average 7.4) than negative farms (average 7.1) but the difference was not significant (Table 3).

Table 2 Brucella abortus positive cattle farms in Maasai Mara national reserve (Kenya) and occurrence of abortions

\begin{tabular}{llcc}
\hline & Farm with abortion & Farm without abortion & Total \\
\hline Positive farm & 13 & 7 & 20 \\
Negative farm & 25 & 30 & 55 \\
Total & 38 & 37 & 75 \\
\hline
\end{tabular}


Table 3 Study on Brucella abortus seropositivity in cattle of three villages around Maasai Mara national reserve (Kenya): herd characteristics and results from a questionnaire on risk practices and clinical signs compatible with brucellosis in cattle and in humans handling livestock

\begin{tabular}{|c|c|c|c|c|}
\hline & Overall $(\mathrm{N}=75)$ & Lemek $(\mathrm{N}=25)$ & Mara Rianta $(\mathrm{N}=25)$ & Endoinyo Narasha $(\mathrm{N}=25)$ \\
\hline Cattle herd size & $109(5-400)$ & $97(15-300)$ & $144(14-400)$ & $85(5-300)$ \\
\hline Years of operation & $34.6(5-70)$ & $35.32(15-60)$ & $37.08(15-70)$ & $31.44(5-70)$ \\
\hline Grazing in reserve & $60 \%$ & $32 \%$ & $100 \%$ & $48 \%$ \\
\hline Bought livestock during the last year & $79 \%$ & $88 \%$ & $64 \%$ & $84 \%$ \\
\hline \multicolumn{5}{|l|}{ Contact with wildlife reported by the farmer } \\
\hline Ungulates & $100 \%$ & $100 \%$ & $100 \%$ & $100 \%$ \\
\hline Predators & $76 \%$ & $52 \%$ & $100 \%$ & $76 \%$ \\
\hline Monkeys & $35 \%$ & $0 \%$ & $36 \%$ & $68 \%$ \\
\hline \multicolumn{5}{|c|}{ Contact with other livestock reported by the farmer } \\
\hline Cattle & $100 \%$ & $100 \%$ & $100 \%$ & $100 \%$ \\
\hline Goats & $80 \%$ & $92 \%$ & $48 \%$ & $100 \%$ \\
\hline Sheep & $80 \%$ & $92 \%$ & $48 \%$ & $100 \%$ \\
\hline Pigs & $0 \%$ & $0 \%$ & $0 \%$ & $0 \%$ \\
\hline Poultry & $0 \%$ & $0 \%$ & $0 \%$ & $0 \%$ \\
\hline \multicolumn{5}{|l|}{ Signs of illness noticed in cattle } \\
\hline Fever & $4 \%$ & $8 \%$ & $4 \%$ & $0 \%$ \\
\hline Fatigue & $0 \%$ & $0 \%$ & $0 \%$ & $0 \%$ \\
\hline Reduced fertility/abortion and/or stillbirth & $51 \%$ & $48 \%$ & $68 \%$ & $36 \%$ \\
\hline Decrease in milk production & $9 \%$ & $12 \%$ & $4 \%$ & $12 \%$ \\
\hline Mastitis/udder swelling and/or pain & $23 \%$ & $32 \%$ & $24 \%$ & $12 \%$ \\
\hline \multicolumn{5}{|c|}{ Self-reported signs of illness experienced by people handling the animals } \\
\hline Fever & $45 \%$ & $44 \%$ & $48 \%$ & $40 \%$ \\
\hline Sweats & $15 \%$ & $16 \%$ & $16 \%$ & $12 \%$ \\
\hline Malaise & $31 \%$ & $20 \%$ & $20 \%$ & $52 \%$ \\
\hline Headache & $57 \%$ & $60 \%$ & $48 \%$ & $64 \%$ \\
\hline Pain in muscles, joints and/or back & $57 \%$ & $56 \%$ & $52 \%$ & $64 \%$ \\
\hline
\end{tabular}

\section{Discussion}

More than a fifth of the farms and a tenth of the cattle had evidence of past Brucella infection in this study, with higher odds of animals being positive closer to the national reserve. To our knowledge, no similar study has been carried out on Brucella in this context. In addition, both livestock and humans had experienced symptoms that are consistent with the pathogen. Although this was not assessed in this study, it is possible that some clinical signs were caused by brucellosis. Indeed, human Brucella infections and disease have been previously reported in Kenya $[9,10]$.

There may be different explanations to the higher seroprevalence in Mara Rianta observed here. While all sites practices natural breeding, which has been associated with higher risk of brucellosis [11], all three positives males were in Mara Rianta, which may indicate a higher infection rate in the males in that population, further increasing the risks for the females. However, due to the small number of males sampled in this study, further research is needed to conclude on this. It is likely that a larger herd size entails a greater risk for Brucella infection. Previous studies suggest small, confined herds have lower risks [3], which is supported by the results from this study where Endoinyo Narasha was the village with the lowest prevalence, the smallest herds, and the only village where cattle farms were fenced.

There is a possibility that cattle in the infected farms have had abortions earlier since most cattle only abort once after infection [5], and we found a tendency among positive farms to report a higher degree of reproductive problems. There are many reasons why cattle may abort, and many of these are infectious [12]. Further studies are needed to investigate the relative importance of Brucella spp. as a cause of abortion in cattle of the examined area. Similarly the symptoms reported by farmers may be caused by many different diseases, and further studies would be required to provide more insight knowledge on the contribution of different pathogens to the total disease burden. 
Wildlife can be a source of infectious diseases and thereby a risk to the health of the livestock as has been shown for some diseases [13]. A significant difference was found in prevalence of brucellosis between the villages, with cattle from Mara Rianta having the highest proportion of positive animals. These animals were grazing inside the national reserve Maasai Mara, and interacting with wildlife to a higher degree, than cattle that mostly graze behind fences within the own village, as in Endoinyo Narasha. Brucella exposure has been reported in both African buffaloes (Syncerus caffer), blue wildebeest (Connochaetes taurinus), oryx (Oryx beisa) and eland (Taurotragus oryx); common in and around Maasai Mara [14, 15].

Brucellosis remains an important problem in Kenya since there is currently no possibility of controlling or eradicating the disease the same way as in high-income countries, and vaccination is not common. None of the participating farmers reported that they had vaccinated their animals against the disease. In Kenya, a suitable method of controlling disease has to be introduced, with components of disease surveillance, mapping of transmission routes, vaccination campaigns, isolation of exposed animals and thorough examination before introducing new individuals to a healthy animal herd ought to be fundamental since all mentioned factors are important cornerstones in successful disease control. Since there are no vaccines available for humans, prevention of brucellosis in humans relies fully in controlling the animal reservoir.

\section{Limitations}

This study had several limitations, including the limited sample size of 75 herds, and few males sampled. Although selection of animals at herd level was intended to be unbiased and random, large bulls and aggressive individuals were excluded; however, the authors are not expecting this to influence the results significantly. There were many confounders in the study, and herd size was much depending on the area of sampling, meaning that it is difficult to draw definite conclusions on these factors. To fully evaluate the impact on human health, it would be necessary to collect data on incidence and morbidity.

\section{Additional files}

Additional file 1. Questionnaire. This file is containing the questions for the interviews with farmers.

Additional file 2. Additional table with all data. This file is containing all data collected and analyzed.

\section{Abbreviations}

Cl: confidence interval; ELISA: enzyme-linked immunosorbent assay; IACUC: Institutional Animal Care and Use Committee; ILRI: International Livestock Research Institute; OR: odds ratio.

\section{Authors' contributions}

SE conducted the field and laboratory work, data analyses, and did the first draft of the manuscript. DN supervised the field work and contributed to the study design and manuscript. BB and SA contributed to the study design and manuscript. AK contributed to the field work, the study design and manuscript. JL supervised all the work, analyses, and manuscript writing; and designed the study. All authors read and approved the final manuscript.

\section{Author details \\ ${ }^{1}$ Department of Clinical Sciences, Swedish University of Agricultural Sciences, Uppsala, Sweden. ${ }^{2}$ Department of Biosciences, International Livestock Research Institute, Nairobi, Kenya. ${ }^{3}$ Department of Biological Sciences, University of Embu, Embu, Kenya. ${ }^{4}$ Department of Biosciences, International Livestock Research Institute, Addis Ababa, Ethiopia. ${ }^{5}$ Department of Medical Biochemistry and Microbiology, Uppsala University, Uppsala, Sweden.}

\section{Acknowledgements}

We thank livestock owners, local animal health worker William Kububuk and John Kisurkat who participated in the survey. We are also grateful to the Kenya Wildlife Service (KWS) for laboratory space at Sekenani that allowed us to prepare serum for serological analysis.

\section{Competing interests}

There were no competing interests, financial or others, in this study.

\section{Availability of data and materials}

The dataset supporting the conclusions of this article is included within the article as an Additional files.

\section{Consent for publication}

Not applicable.

\section{Ethical approvals and consent to participate}

The study had an ethical approval from ILRI animal care and use committee (IACUC Approval 2016-20). All participants were informed about the purpose of the study, and asked for their consent. Written informed consent was given by owners before interview or sampling.

\section{Funding}

This work was supported by SIDA, Swedish International Development Cooperation, through MFS, Minor Field Study, grants. Additional support was provided by Consultative Group for International Agricultural Research (CGIAR) Research Program on Agricultural for Nutrition and Health (A4NH) led by International Food Policy Research Institute (IFPRI) and the AfricanBioServices Project which received funding from the European Union's Horizon 2020 research and innovation programme under Grant Agreement No 641918.

\section{Publisher's Note}

Springer Nature remains neutral with regard to jurisdictional claims in published maps and institutional affiliations.

Received: 10 August 2017 Accepted: 15 November 2017

Published online: 25 November 2017
References

1. Thumbi SM, Njenga MK, Marsh TL, Noh S, Otiang E, Munyua P, et al. Linking human health and livestock health: a "one-health" platform for integrated analysis of human health, livestock health, and economic welfare in livestock dependent communities. PLoS ONE. 2015;10:e0120761. https://doi.org/10.1371/journal.pone.0120761.

2. Grace D, Wanyoike F, Lindahl J, Bett B, Randolph T, Rich KM. Poor livestock keepers: ecosystem-poverty-health interactions. Philos Trans R Soc B Econ. 2017;372:20160166.

3. McDermott JJ, Arimi S. Brucellosis in sub-Saharan Africa: epidemiology, control and impact. Vet Microbiol. 2002;90:111-34. https://doi. org/10.1016/S0378-1135(02)00249-3. 
4. OIE. Infection with Brucella abortus, Brucella melitensis and Brucella suis. In: OIE Terrestrial Manual 2016. Rome, Italy, OIE (World Organisation for Animal Health); 2016.

5. Godfroid J, Nielsen K, Saegerman C. Diagnosis of brucellosis in livestock and wildlife. Croat Med J. 2010;51:296-305.

6. Godfroid J, Scholz HC, Barbier T, Nicolas C, Wattiau P, Fretin D, et al. Brucellosis at the animal/ecosystem/human interface at the beginning of the 21st century. Prev Vet Med. 2011;102:118-31.

7. Rhyan JC, Nol P, Quance C, Gertonson A, Belfrage J, Harris L, et al. Transmission of brucellosis from elk to cattle and bison, Greater Yellowstone area, U.S.A., 2002-2012. Emerg Infect Dis. 2013;19:1992-5. https://doi. org/10.3201/eid1912.130167.

8. Omemo P, Ogola E, Omondi G, Wasonga J, Knobel D. Knowledge, attitude and practice towards zoonoses among public health workers in Nyanza province, Kenya. J Public Health Africa. 2012;3:22. https://doi.org/10.4081/ jphia.2012.e22.

9. de Glanville WA, Conde-Álvarez R, Moriyón I, Njeru J, Díaz R, Cook EAJ, et al. Poor performance of the rapid test for human brucellosis in health facilities in Kenya. PLoS Negl Trop Dis. 2017;11:e0005508. https://doi. org/10.1371/journal.pntd.0005508.
10. Cook EA. Epidemiology of zoonoses in slaughterhouse workers in western Kenya. 2014. https://cgspace.cgiar.org/handle/10568/56864. Accessed 15 Jul 2015

11. Basit A, Rahim K, Shahid M, Saleha S, Ahmad S. Comparative study of brucellosis in different breeding practices of cattle and buffaloes. J Inf Mol. 2015;34:86-9.

12. Hovingh E. Abortions in dairy cattle i: common causes of abortions. Virginia cooperative extension; 2009. https://vtechworks.lib.vt.edu/handle/10919/48400. Accessed 8 May 2017.

13. Michel AL, Bengis RG. The African buffalo: a villain for inter-species spread of infectious diseases in southern Africa. Onderstepoort J Vet Res. 2012;79:453.

14. Paling RW, Waghela S, Macowan KJ, Heath BR. The occurrence of infectious diseases in mixed farming of domesticated wild herbivores and livestock in Kenya II. Bacterial diseases. J Wildl Dis. 1988;24:308-16. https:// doi.org/10.7589/0090-3558-24.2.308.

15. Waghela S, Karstad L. Antibodies to Brucella spp. among blue wildebeest and African buffalo in Kenya. JWildl Dis. 1986;22:189-92. https://doi. org/10.7589/0090-3558-22.2.189.

\section{Submit your next manuscript to BioMed Central and we will help you at every step:}

- We accept pre-submission inquiries

- Our selector tool helps you to find the most relevant journal

- We provide round the clock customer support

- Convenient online submission

- Thorough peer review

- Inclusion in PubMed and all major indexing services

- Maximum visibility for your research

Submit your manuscript at www.biomedcentral com/submit 